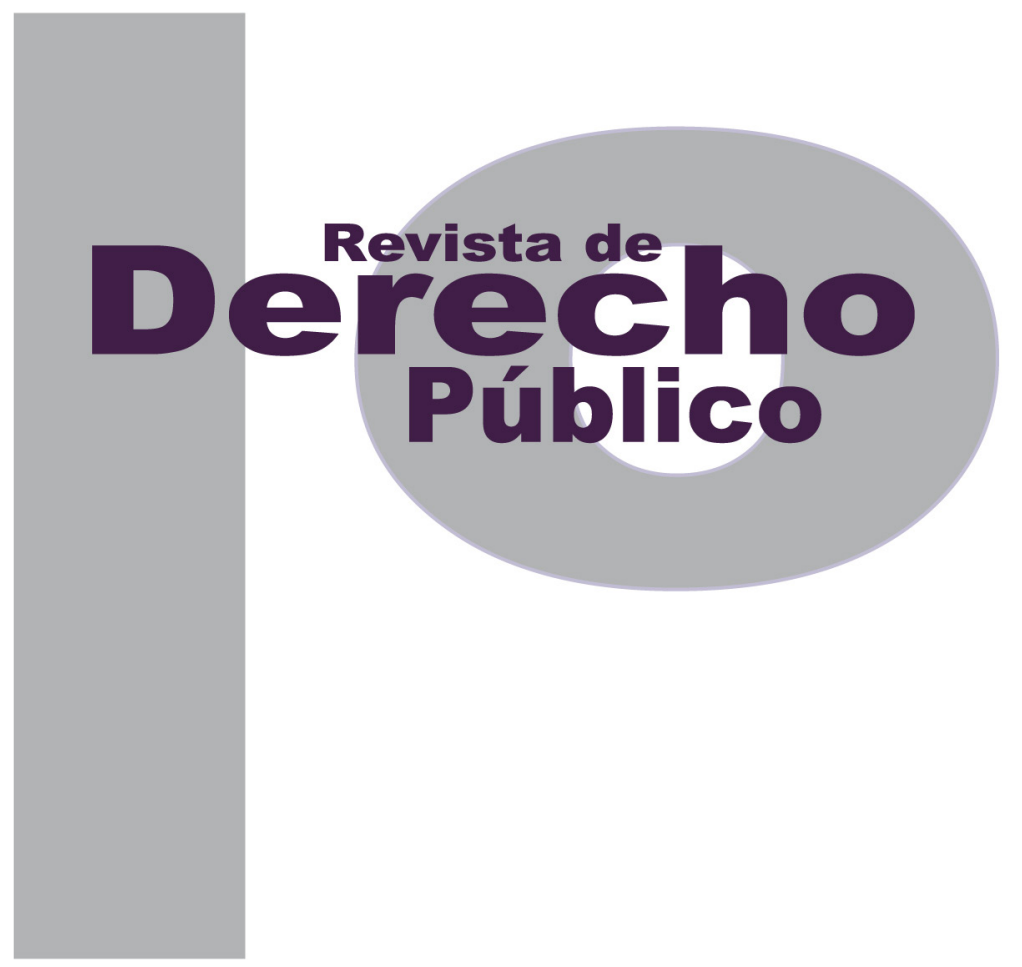

\title{
LA POLÍTICA DE DESCONGESTIÓN JUDICIAL 2009-2014, UN COSTOSO E INEFICIENTE ESFUERZO
}

\author{
RICARDO ANDRÉS RICARDO EZQUEDA
}

Artículo de reflexión

DOI: http://dx.doi.org/10.15425/redepub.36.2016.06

Universidad de los Andes

Facultad de Derecho

Rev. derecho publico No. 36

enero - junio de 2016. e-ISSN 1909-7778 


\section{La política de descongestión judicial 2009-2014, un costoso e ineficiente esfuerzo Resumen}

El problema de la congestión judicial en nuestro país se ha tornado, en la actualidad, en uno de los mayores deslegitimadores de la función pública que ejerce la Rama Jurisdiccional. Debido a dicha problemática, la mayor parte de los colombianos ven coartados, en el día a día, múltiples derechos fundamentales como el acceso a la justicia y a la tutela judicial efectiva. Por tal motivo, el propósito principal del presente artículo de reflexión es brindarle tanto al ámbito académico, en especial a los alumnos, como a las personas del común, un texto introductorio a la política pública de descongestión judicial que actualmente se ejecuta con Colombia, con miras a que se conozcan sus principales fortalezas, deficiencias y necesidades de cambio.

Palabras clave: descongestión judicial, Rama Judicial, crisis de la justicia, oralidad, Código General del Proceso.

\section{Policies to relieve judicial congestion 2009-2014. A costly and inefficient effort}

\section{Abstract}

The judicial congestion issue in our country has become one of the greatest causes for the loss of legitimacy of the civil service performed by the Judicial Branch. Due to this issue, most Colombian citizens are restricted on a daily basis from the exercise of multiple fundamental rights such as the access to justice and the effective judicial protection. That is why the main purpose of this reflective essay is to introduce people from the law academy, especially students, as much as non-academics, to the current Colombian judicial decongestion public policy, showing its main strengths, weaknesses and changing needs.

Key words: judicial decongestion, judicial Branch, justice crisis, orality, General Code of Process.

\section{A política de descongestão judicial 2009-2014, um caro e ineficiente esforço}

\section{Resumo}

O problema da congestão judicial em nosso país tem se tornado, atualmente, em um dos maiores deslegitimadores da função pública que exerce a Rama Jurisdicional. Devido à dita problemática, a maior parte dos colombianos veem coartados, no dia a dia, múltiplos direitos fundamentais como o acesso à justiça e à tutela judicial efetiva. Por tal motivo, o propósito principal do presente artigo de reflexão é brindar tanto ao âmbito acadêmico, em especial aos alunos, como às pessoas do comum, um texto introdutório sobre a política pública de descongestão judicial que atualmente se executa na Colômbia, com o objetivo de que se conheçam suas principais fortalezas, deficiências e necessidades de mudança.

Palavras-chave: descongestão judicial, Rama Judicial, crise da justiça, oralidade, Código General do Processo. 


\title{
La política de descongestión judicial 2009-2014, un costoso e ineficiente esfuerzo*
}

\author{
RICARDO ANDRÉS RICARDO EZQUEDA**
}

\begin{abstract}
SUMARIO
Introducción - I. MOTIVACIONES Y METODOLOGÍA - II. CÓDIGO GENERAL DEL PROCESO, RESPUESTA A LA CONGESTIÓN JUDICIAL - III. MEDIDAS DE DESCONGESTIÓN A PARTIR DE LA LEY 1285 DE 2009 - A. Inicios - B. La Ley 1395 de 2010 y los ajustes procesales - C. 2013 y 2014, modificaciones menores y confirmación de pronósticos - IV. ESTRATEGIAS DEL PLAN DE IMPLEMENTACIÓN DEL CÓDIGO GENERAL DEL PROCESO - V. EVENTUALES PROBLEMAS DE LAS MEDIDAS ADOPTADAS EN COLOMBIA - A. Escogencia de jueces de descongestión y su "atrincheramiento" - B. Exigencia de metas e incentivos pecuniarios por aumento en la productividad - C. La experiencia del Nuevo Código de Procedimiento Administrativo y de lo Contencioso Administrativo (CPACA), la división de despachos - VI. CONCLUSIONES - Referencias.
\end{abstract}

* Cómo citar este artículo: Ricardo Ezqueda, R. A. (Junio, 2016). La política de descongestión judicial 2009-2014, un costoso e ineficiente esfuerzo. Revista de Derecho Público, (36). Universidad de los Andes (Colombia). DOI: http://dx.doi.org/10.15425/ redepub.36.2016.06

** Abogado con Opción en Gobierno, de la Universidad de los Andes (2014). Actualmente se encuentra cursando Especialización en Derecho Administrativo en la Universidad del Rosario. Participó como orador en concursos internacionales de Derecho Procesal representando a la Universidad de los Andes. En la actualidad se desempeña como abogado en la firma de derecho minero Ricaurte Rueda Abogados, es tutor en el área de Derecho Procesal y funge como coach del Grupo de Semilleros de Derecho Procesal de la Universidad de los Andes. Correo: ra.ricardo2319@uniandes.edu.co

Debo agradecer muy especialmente al profesor Diego López Medina por su especial guía en la reflexión y discusión de estas ideas, al Dr. Manuel Ezqueda y a Betty Benito por su tiempo y apoyo desde que todo comenzó. 
Introducción

Actualmente la justicia colombiana está pasando por una difícil crisis institucional que afecta gravemente la percepción que el ciudadano común tiene respecto a su aparato de impartición de justicia. Tal dificultad nace, especialmente, de la concepción de lentitud, corrupción y deshumanización de la Rama Jurisdiccional y de los funcionarios que laboran en ella. De acuerdo con lo expuesto, puede afirmarse que la principal estrategia en cuanto a recursos invertidos que han considerado el Gobierno Nacional y el Consejo Superior de la Judicatura (CSJ) para enfrentar el fenómeno descrito ha sido la política de descongestión judicial.

Surge entones un cuestionamiento: ¿Por qué está política pública es considerada como la de más alta relevancia al momento de cambiar la imagen de la justicia de nuestro país? Frente a dicho interrogante pueden plantearse varias respuestas: a) Que un aparato de justicia sin congestión permite atender los derechos de los ciudadanos de manera más eficiente, garantizándoles su derecho a la tutela judicial efectiva; b) Que únicamente con despachos descongestionados podrá ponerse en marcha la oralidad, un modelo procesal más trasparente, rápido y efectivo; y finalmente, c) Que la política de descongestión al traer consigo más empleados a la Rama Judicial permite ampliar la cobertura y la capacidad de respuesta de esta.

Sin importar si una o todas las alternativas expuestas son verídicas desde un punto de vista material, lo cierto es que la política pública de descongestión actualmente aumenta la capacidad instalada de la Rama Jurisdiccional en una proporción de cerca de $1 / 5$, pues de los 48.000 empleados con que cuenta actualmente, más de 8.000 hacen parte del Plan Nacional de Descongestión -PNDG (CSJ, 2013, p. 172). Tan importante es la participación de los citados funcionarios dentro del esquema actual de la justicia colombiana que cada trimestre, desde los últimos cuatro años, todo el aparato judicial se detiene (entra en cese de labores) cada vez que se anuncia que los recursos destinados al PNDG se encuentran a punto de agotarse.

Teniendo en cuenta la problemática expuesta, a través del presente escrito he querido realizar un estudio puntual de las medidas de descongestión que se han empleado en Colombia a partir de la promulgación de la Ley 1285 de 2009, con énfasis en la jurisdicción ordinaria en su especialidad Civil, de la mano del Plan de Implementación del nuevo Código General del Proceso (CGP). Esta disertación no pretende, entonces, limitarse a exponer simplemente las bases de la citada estrategia, adicionalmente tiene como fin servir de texto guía para una primera aproximación del público en general a la política de descongestión judicial y a los problemas que se han derivado de su aplicación.

Para cumplir con tales fines el escrito lo he dividido en seis apartes. Antes de desarrollar el contenido específico mostraré la motivación que fungió como impulsora principal de la investigación; en el segundo acápite expondré brevemente la razón que dio origen al nuevo 
estatuto procesal civil y a su plan de descongestión; continúo con una descripción sucinta de las medidas de descongestión implementadas a nivel nacional desde sus orígenes en el año 2009, partiendo de la Ley 1285 del mismo año y culminando con los últimos acuerdos expedidos por el CSJ en el último trimestre del 2014, a partir de lo cual presento unos breves razonamientos derivados de las observaciones empíricas respecto a la inoperancia pasada y actual de las medidas de descongestión judicial colombianas.

Esta última afirmación obedece a que las medidas hasta ahora empleadas han presentado un sin número de problemas al momento de su implementación, y como consecuencia de ello hoy en día nuestra administración de justicia sigue siendo lenta, ampliamente cuestionada por el público en general y poco eficaz, tal como lo evidencian los cerca de 2.000.000 de procesos a la espera de una pronta resolución. ${ }^{1}$ Es decir, de antemano puedo afirmar que los esfuerzos administrativos emprendidos por el CSJ han sido insuficientes para descongestionar nuestra justicia no solo por su casi exclusivo enfoque de creación de cargos, sino también por la falta de reacción de dicho ente ante los malos resultados. Por tanto, hoy en día, el problema de la congestión sigue siendo una de las principales preocupaciones en cuanto a justicia no solo desde la visión de los usuarios y de la consolidación de su derecho de acceso a esta, sino también desde la academia, los funcionarios judiciales y la opinión pública en general.

La cuarta parte del presente escrito consta de un diagnóstico sobre las estrategias que están llevando a cabo los distintos actores que participan en la puesta en marcha del CGP, en cuanto al componente de descongestión se refiere. En el quinto aparte traigo a colación unos breves señalamientos de experiencias comparadas que me permiten sugerir algunas estrategias para afrontar el problema central objeto de este escrito, y así proponer soluciones alternativas a la creación de funcionarios de descongestión (v. gr. mejoras metodológicas de trabajo como los modelos de gestión administrativa). Finalmente presento unas breves conclusiones extraídas de lo expuesto a lo largo de esta investigación.

\section{MOTIVACIONES Y METODOLOGÍA}

A lo largo de los años, los distintos actores de la justicia han estudiado el problema de la congestión judicial desde diferentes enfoques. Por un lado, el CS」 ha realizado múltiples investigaciones cuantitativas plasmadas en sus informes al Congreso de la República ${ }^{2}$ sobre el estado actual de la justicia en el país. Este mismo cuerpo colegiado, también ha efectuado análisis combinados entre la metodología

1. La cifra exacta era de 1.698 .233 procesos represados a diciembre de 2014 (CSJ, 2015).

2. Ver, por ejemplo, Consejo Superior de la Judicatura. Informe anual al Congreso de la República, años 2010,2011 y 2012. 
antes citada y el método cualitativo, como por ejemplo el informe Atraso judicial en Colombia: realidades y soluciones (CSJ, 2004). No obstante lo anterior, es claro que la mencionada problemática sigue siendo un flagelo que afecta el derecho a la tutela judicial efectiva de todos los colombianos, sin una solución palpable a corto o mediano plazo.

Desde mi concepción, existe entonces un vacío en los estudios hasta ahora desarrollados sobre congestión judicial, puesto que no han podido conjurar significativamente las causas y consecuencias de esta en el país; ello sin mencionar que el material bibliográfico dedicado al estudio concreto de las medidas de descongestión es prácticamente nulo en nuestro entorno. Para justificar los anteriores planteamientos, en esta sección realizo un breve recuento de los más significativos textos dedicados al análisis de la política de descongestión emprendida en Colombia, agrupándolos de acuerdo con las categorías: metodología empleada y estudio concreto o no de las medidas de descongestión.

Para mayor claridad debo destacar que la categoría metodología empleada hace referencia a si el texto, para desarrollar la investigación, usa un enfoque cualitativo, cuantitativo o comparativo de acuerdo con las definiciones esbozadas por Charles Ragin (2007) y Mike McConville (2007). Adicionalmente, debo señalar que la categoría estudio concreto o no de las medidas se deriva de indagar si el texto estudiado efectúa un análisis exhaustivo de las medidas de descongestión judicial o se limita simplemente a explicar las causas que generan la mora dentro de la Rama Jurisdiccional.

De acuerdo con lo expuesto iniciaré reseñando el primer y más grande grupo de escritos. Estos emplean un enfoque de investigación cuantitativo, dado que realizan análisis a partir de la revisión de muchos casos condensados en estadísticas que permiten efectuar inferencias respecto del estado actual de la justicia. Como ejemplo de lo expuesto pueden citarse: los informes anuales del CSJ al Congreso de la República y los planes sectoriales de desarrollo de la Rama Judicial elaborados por el mismo cuerpo colegiado, y el texto Unificación de procedimientos y sus términos procesales en materia civil como solución a la congestión de despachos judiciales en Bogotá, D. C, de Moreno Moreno y Malagón Martínez (2008), editado por la Universidad La Gran Colombia.

Este tipo de trabajos tienen como común denominador la gran amplitud de su componente diagnóstico sobre el tema de la congestión, y el uso de cifras acompañadas de análisis cuantitativos que soportan el argumento respecto a la necesidad del uso de medidas de choque para afrontar la problemática señalada. Si bien tal aporte lo considero de gran relevancia, solo conforma el primer paso necesario para conjurar de manera satisfactoria la problemática allí reseñada.

Otros textos analizados denotan metodologías diferentes a la anteriormente esbozada. Autores como Mabel Londoño Jaramillo, La congestión y la mora judicial: el juez, ¿su único responsable? 
(2008) y Sergio Clavijo, Costos y eficiencia de la Rama Judicial en Colombia, políticas de choqueoperativo (2011), usan enfoques cualitativos para estudiar el problema de la congestión desde un caso particular: la jurisdicción, entendida como única y un todo, restringiendo así el tamaño de la muestra. Vale la pena destacar frente al escrito de Clavijo, la mezcla interesante que realiza entre el método cualitativo y el comparativo, pues se vale de experiencias foráneas para aportar soluciones a la justicia colombiana.

En cuanto a la categorización estudio concreto o no de las medidas de descongestión debo señalar que la mayoría de escritos analizados no realizan un examen pormenorizado de la política pública objeto de estudio, puesto que se limitan simplemente a diagnosticar la mora judicial y a sugerir soluciones sin ahondar en la implementación de estas. Como ejemplo de este tipo de textos puede citarse el artículo "Reflexiones sobre la congestión judicial en la Jurisdicción de lo Contencioso Administrativo", de Leonardo Torres Calderón (2002).

No obstante lo anteriormente reseñado, debo destacar que si bien algunos escritos como los informes al Congreso de la República provenientes del CSJ contienen datos respecto al desempeño de las medidas de descongestión, estos no son analizados ni en el ámbito académico ni en el judicial, lo que impide una retroalimentación valiosa para el mejoramiento de la política pública en estudio.

Teniendo en cuenta la existencia del citado vacío, en este artículo pretendo realizar un apor- te al estudio de las medidas de descongestión puestas en marcha en nuestro país, desde varios enfoques metodológicos. Por un lado, me valdré del método cualitativo para examinar las cifras de desempeño de la política de descongestión desde 2009 y una muestra pequeña pero significativa de las medidas de descongestión y los resultados de estas frente a la tasa de evacuación de procesos, concretamente las relacionadas con la creación de despachos transitorios y nombramiento de funcionarios provisionales, todo esto con el fin de determinar si son viables desde una mirada de costo-beneficio. Finalmente, también emplearé la herramienta comparativa para explorar casos exitosos de derecho extranjero, útiles en cuanto a conocer posibles soluciones empleadas en otras jurisdicciones como la brasilera, uruguaya o estadounidense frente al problema central de este escrito.

\section{CÓdIGO GENERAL DEL PROCESO, RESPUESTA A LA CONGESTIÓN JUDICIAL}

Antes de iniciar con la exposición del tema que nos atañe considero adecuado y necesario que se proponga una definición unívoca del problema a dilucidar a través del presente escrito, a saber: la falta de conocimiento del contenido y objeto de las medidas de descongestión judicial en Colombia. Sin embargo, para poder entender el fenómeno bajo estudio es menester previamente definir qué es lo que impulsa la aplicación de medidas de descongestión judicial, es decir, debe tenerse presente la definición del término congestión judicial. 
Según algunos doctrinantes, este defecto del sistema se presenta cuando "el aparato judicial establecido por la Constitución y la ley, no es capaz de responder oportunamente a las necesidades de las personas" (Torres, 2002, p. 4).

Londoño (2008) aporta una de las definiciones de congestión judicial existentes en la literatura y añade otra muy pertinente: la de atraso endémico. Esto es lo que nos dice:

Entendida [la congestión judicial] como el volumen de la demanda superior a la capacidad razonable de respuesta de la Rama Judicial, y el atraso endémico de la justicia, entendido como la demora en la definición de la controversia jurídica sometida a consideración del juez, respecto del tiempo normativo establecido para la decisión del mismo. (P. 358).

Otros expertos exponen que la congestión judicial puede definirse mediante tres conceptos clave:

Demora judicial o mora: Es el exceso en el tiempo real de gestión del proceso respecto del tiempo normativo establecido para la decisión del mismo, con ocasión de acciones u omisiones del magistrado o juez, por (i) causas administrativas o (ii) causas culturales.

Atraso: Es el volumen importante de asuntos que permanecen en los despachos judiciales durante periodos largos sin resolver en contradicción a los mandatos legales.
Congestión o sobrecarga: Es el volumen de demanda de justicia superior a la capacidad razonable de respuesta de la Rama Judicial, originada en los factores: (i) Acumulación, (ii) de naturaleza normativa, (iii) de gestión de agentes externos, (iv) de naturaleza administrativa, (v) por inadecuadas prácticas litigiosas y (vi) de judicialización excesiva (Corporación Excelencia de la Justicia, 2007, p. 4). [Énfasis fuera del texto].

Aclarado lo anterior debo decir que la máxima autoridad de gobierno judicial ha buscado por varios años eliminar el represamiento de procesos en los despachos por medio de diversas medidas de descongestión. Tales decisiones de descarga de procesos del aparato jurisdiccional hacen parte de una política pública que busca garantizar el acceso a la justicia de los ciudadanos de nuestro país, por medio de estrategias gerenciales que tienen como función principal el equilibrio del mercado de justicia, al tratar de mantener un balance adecuado entre demanda y oferta de dichos servicios.

Es importante destacar que los administradores de la justicia no son los únicos que han esbozado preocupaciones frente al tema. El Gobierno nacional en el Plan Nacional de Desarrollo 2010-2014 Prosperidad para todos (2011) señaló la importancia de tener un sistema judicial eficiente y descongestionado; en la misma línea, el cSJ en el Informe al Congreso de la República 2011 destaca la congestión judicial como uno de los principales problemas que los usuarios de la justicia deben enfrentar. Esto se debe a varias razones: incremento del 
$205 \%$ en la demanda de justicia entre los años 1993-2011; barreras al acceso a la justicia de tipo económico, geográfico y educativo; incumplimiento cada vez mayor en las obligaciones contractuales entre las partes; aumento en la conflictividad social; ineficacia de las medidas de descongestión puestas en marcha hasta el momento, entre otras.

Gráfica 1. Histórico de los ingresos y egresos de despachos permanentes (1995-2010)

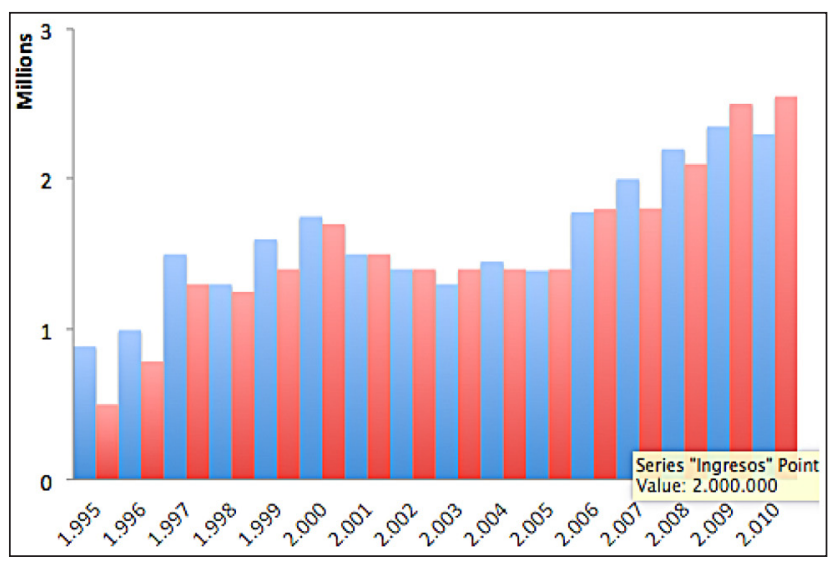

Azul: ingresos

Rojo: egresos.

Fuente: construcción propia a partir de: CSJ. Informe al Congreso de la República 2012, p. 94.

La gráfica 1 demuestra claramente la situación señalada y permite evidenciar cómo, en la mayoría de los años estudiados, la oferta de justicia ha sido menor a las necesidades de los usuarios de esta, lo cual explica el déficit o el gran número de procesos que actualmente acumula la Rama Jurisdiccional colombiana. Según
Clavijo (2011), la justicia colombiana se encuentra desde hace varios años en un umbral de eficiencia bajo, al tener represados para el año 2010 un total de 6.337 procesos por cada 100.000 habitantes, superando ampliamente el promedio de su vecindad que se acerca a los 3.000 procesos represados por cada 100.000 habitantes (p. 34), y entre las causas menciona:

El sector judicial colombiano enfrenta una elevada carga por cuenta del alto grado de conflicto social del país, un problema de carácter estructural. Ello se ve agravado por fallas en su regulación, donde los códigos de procedimiento continúan siendo complejos y de difícil evacuación, a pesar de las continuas reformas a los mismos. Además, el uso indiscriminado de las tutelas contra sentencias judiciales ha venido a entorpecer aún más la situación. (P. 72).

En el mismo sentido, autores como Miguel Enrique Rojas Gómez (2011, p. 15) han destacado la grave situación que afronta la impartición de justicia en nuestro país, y llegan a afirmar que nos encontramos ante un inocultable estado de cosas inconstitucional dado que con ello se incumplen los compromisos internacionales de nuestra nación en cuanto a procesos de duración razonable se refiere, lo que trae como consecuencia que el discurso de los derechos humanos se torne estéril. ${ }^{3}$

3. Rojas (2011, p. 15), citando a la Corte Constitucional: “La mora judicial, tal como lo ha entendido esta corporación, viola el primado constitucional de acceso a la administración de justicia cuando la dilación en el trámite de una actuación es originada no en la complejidad del asunto o en la existencia de problemas estructurales de exceso de carga laboral de los funcionarios, sino en la falta de diligencia y en la omisión sistemática de sus deberes por parte de los mismos" (Sentencia T-1249/2004, H. Sierra). 
Teniendo en cuenta lo anterior, el Ejecutivo en su Plan Nacional de Desarrollo 2010-14 propuso cuatro líneas principales de acción para atacar la problemática antes mencionada: la oralidad, la flexibilización y armonización de los procedimientos, la promoción del acceso a la justicia en las llamadas zonas de consolidación y el fortalecimiento de los métodos alternativos de solución de conflictos (MASC). Con el fin de poner en marcha dichas estrategias se promovió en el Legislativo la reforma al estatuto procesal de la Jurisdicción Civil y Comercial dando así nacimiento al nuevo CGP, el cual ordenó a través de su artículo 618 que se elaborara lo más pronto posible, por parte del csJ, un plan especial de descongestión y desconcentración de servicios judiciales según la demanda y la oferta de justicia.

A continuación presentaré las medidas de descongestión más importantes implementadas por el CSJ en el periodo 2009-2014, con el fin de brindarle herramientas al lector para que juzgue si las empleadas por dicho ente en 2013 y 2014 pueden ser rotuladas como novedosas o si simplemente constituyen una continuación del PNDG iniciado en 2009, el cual ha rendido frutos mínimos hasta el momento, no pudiendo evitar una eventual parálisis de la Rama como alguna vez lo dijo el expresidente del Consejo de Estado. Alejandro Ordóñez Maldonado:

Tal vez, una de las circunstancias que más afecta la credibilidad que el Estado debe te- ner frente al ciudadano común y que más lesiona su legitimidad, es la carencia de justicia, siendo la morosidad causa generadora de insatisfacción y a la postre de proliferación de soluciones extrainstitucionales. (Citado por Younes y Mejía, 2006, p. 15)

\section{MEDIDAS DE DESCONGESTIÓN A PARTIR DE LA LEY 1285 DE 2009}

Antes de iniciar con la descripción objeto de este acápite debo aclarar una cuestión metodológica. Si bien antes de la expedición de la Ley 1285 de 2009 existían algunas políticas de descongestión, estas no estaban dirigidas a un nivel macro del sistema sino focalizadas en pequeñas medidas con las cuales no se lograba un impacto nacional; como ejemplo podría citar la creación y puesta en marcha de los jueces de paz a través de la Ley 497 de 1999. Decidí tomar como punto de partida el 2009 no solo porque fue el año en que se inició más fervientemente la lucha contra la congestión, ${ }^{4}$ sino también para demarcar un período que me permitiera describir lo mejor posible las medidas de descongestión empleadas sin ser superficiales al tener en cuenta el espacio limitado y al tratar de abarcar un espacio de tiempo demasiado amplio.

\section{A. Inicios}

A partir del año 2008 tanto los actores judiciales como los usuarios y la comunidad en

4. En el año 2009 se promulgó la Ley 1285 y se propuso el Plan Nacional de Descongestión Judicial. 
general tomaron conciencia frente al eventual colapso de la administración de justicia derivado de su alto grado de congestión. Como respuesta el gobierno promulgó la Ley 1285 de 2009 "por medio de la cual se reforma la Ley 270 de 1996 Estatutaria de la Administración de Justicia". La principal innovación de dicha norma fue ordenar en su artículo 1, parágrafo 2 , que las actuaciones que se realicen dentro de los procesos judiciales deberían ser orales y por audiencias, salvo las excepciones de ley. Otras medidas incluidas en la mencionada normatividad son: procurar la unificación de los procedimientos a través de la expedición de nuevos códigos, el arancel judicial, introducción de avances tecnológicos en la Rama, fortalecimiento de los MASC y el otorgamiento de funciones jurisdiccionales a particulares para el ejercicio de dichos métodos, la creación de los jueces de pequeñas causas y competencia múltiple, etc.

Adicionalmente a tales orientaciones generales, el artículo 15 de dicha norma ordenó algunas medidas que se debían implementar de la mano de la creación de un PNDG "justicia al día", que según el artículo 22 debía formularse integramente dentro de los seis meses siguientes a la promulgación de tal normatividad. Las actuaciones más relevantes ordenadas por el artículo 15 fueron: aplicación de la perención en procesos ejecutivos; redistribución de procesos a los despachos con menos carga laboral, por parte del cSJ; creación de cargos de jueces, magistrados y personal de apoyo itinerantes dentro de los despachos ya establecidos; entre otras.
Vale la pena destacar, como lo han hecho previamente autores como Diego López Medina y Miguel Rojas, que el fundamento lógico de estas políticas está en la necesidad de tener despachos descongestionados para poder implementar la oralidad de manera exitosa. Lo anterior es un requisito fundamental para que el nuevo proceso por audiencias no termine colapsando aún más la ya deficiente administración de justicia, debido a que, iniciar la oralidad con déficit de rendimiento, es decir, con carga laboral mayor a cero, solo traería como resultado un atraso aún mayor de los despachos. Lo expuesto se produciría como consecuencia directa de que el juez deba estar presente en todas las actuaciones proferidas por la unidad judicial, disminuyendo así el nivel de evacuación de esta.

Como alternativa apropiada para evitar dicha situación considero interesante replicar en la especialidad Ordinaria Civil lo expuesto por el artículo 304 del Código de Procedimiento Administrativo y de lo Contencioso Administrativo, el cual dispone la división de la Jurisdicción Contenciosa en dos partes, una de las cuales se encargará únicamente de tramitar los procesos ya iniciados en el procedimiento escritural, para así permitir que los nuevos litigios reglados por la Ley 1437 de 2011 se inicien en despachos con carga laboral cero.

En este punto es importante mencionar que muchos respetados procesalistas, entre ellos Ramiro Bejarano y la mayoría de los miembros de la Comisión Redactora del CGP, se han opuesto a la anterior proposición por conside- 
rar que mantener en vigencia dos estatutos procesales dentro de una misma especialidad de la jurisdicción es una idea inconcebible que dificulta aún más la ya compleja labor del litigante colombiano. No obstante mantengo mi posición, pues considero que la división de la Justicia Civil en el mismo sentido que se hizo con la Contenciosa Administrativa es necesaria para la puesta en marcha del nuevo CGP, con despachos que inicien con "carga laboral cero" so pena del fracaso total de la oralidad y de las nuevas instituciones que trae el nuevo estatuto adjetivo civil. Ello aunado a la tenebrosa realidad que actualmente enfrentan los procesalistas civiles por cuenta de que para la fecha de elaboración de este escrito siguen vigentes el Código de Procedimiento Civil (CPC), la reforma de la Ley 1395 de 2010 y algunas normas del CGP, lo que indiscutiblemente ha acrecentado las confusiones de los litigantes y usuarios de dicha especialidad.

Respecto a los resultados de las medidas consagradas en el artículo 15 de la Ley 1285 de 2009, el CSJ en su Informe al Congreso de la República 2009-2010 destacó, frente al tema de la descongestión, que el inventario final de procesos se redujo en el 2009 en 130.000, un $6 \%$ menos con respecto a las cifras del año 2008 (CSJ, 2009, p. 26). Lo anterior se produjo como consecuencia del aumento de la tasa de producción por despacho, que pasó de 456 procesos terminados en el año 2008 a 551 en el 2009. Las cifras anteriormente citadas fueron posibles, según el CSJ, gracias a las inversiones propuestas por el PND, cuyo objetivo principal de consolidar una justicia al día se lograría disminuyendo los procesos en inventarios para contar con cargas razonables en los despachos judiciales; incrementando el número de fallos producidos en las distintas jurisdicciones; estableciendo con otras instituciones del Estado convenios para implementar medidas de descongestión; brindando asesoría jurídica para la efectiva utilización de los servicios de justicia; mejorando los mecanismos existentes; disminuyendo los tiempos procesales; mejorando los procedimientos judiciales. (CSJ, 2012b, p. 95).

Las inversiones que se mencionaron anteriormente ascendieron a $\$ 93.947 .000 .000$, gastados en la creación de 3.158 cargos transitorios, de los cuales 561 correspondieron a funcionarios y 2.597 a empleados para apoyar despachos judiciales congestionados, centros de servicios, oficinas de apoyo judicial, secretarías y relatorías (CSJ, 2010, p. 39). Lo anterior debe compararse con las cifras del año 2008, en el que se crearon 1.820 cargos, de los cuales 249 correspondieron a funcionarios y 1.571 a empleados, por un valor de \$35.605.005.000 millones de pesos (CSJ, 2010, p. 21), lo que según el informe tuvo un impacto favorable pues en contraste con el año 2008 la tasa de egresos aumentó en un 28\% (CSJ, 2010, p. 21).

\section{B. La Ley 1395 de 2010 y los ajustes procesales}

La Ley 1395 de 2010, a diferencia de la 1285 de 2009, introdujo modificaciones procesales con múltiples variaciones al CPC y no se ocu- 
pó de la conformación de la Rama Judicial ni de la creación de cargos. El eje fundamental de esta norma fue la puesta en marcha de la oralidad, remplazando el proceso ordinario escritural tradicional por el proceso verbal por audiencias. Otras dos principales novedades fueron: que los procesos debían ser resueltos en términos perentorios para el juez so pena de perder competencia y ser sometido a investigación disciplinaria (artículo 9) y la reglamentación de las competencias de los jueces de pequeñas causas y competencia múltiple para que estos pudieran entrar en funcionamiento.

Como resultado de estas modificaciones y la continuación de las medidas de descongestión previamente expuestas, el cSJ en su Informe al Congreso de la República 2010-2011 sostuvo que en 2010 disminuyeron los inventarios en 262.271 procesos, para llegar a un inventario total de 2.619.636; en ese mismo año, la Sala Administrativa adoptó medidas transitorias por valor de \$117.301.148.261, representados en la creación de 362 cargos temporales de funcionarios (magistrados y jueces) y de 3.073 cargos de empleados transitorios como sustanciadores, citadores, escribientes, auxiliares judiciales, oficiales mayores y asistentes administrativos, entre otros, con el fin de que se ampliara la oferta del servicio de justicia de manera transitoria (CSJ, 2011, p. 23). Las medidas de descongestión adoptadas en 2010 permitieron la evacuación de 111.572 nuevos procesos. El impacto de lo anterior se evidencia en la disminución del inventario final en 262.271 procesos, es decir, en un 11\% del total de estos, al pasar de 2.881.957 procesos en el 2009 a 2.619.686 en el 2010 (CSJ, 2011, p. 24).

El análisis de las cifras expuestas indica que, si bien el Informe al Congreso de la República 2010-2011 muestra avances en la descongestión especialmente en el tema de los egresos, los resultados no son satisfactorios teniendo en cuenta que cada año ha sido necesario aumentar tanto el presupuesto para la creación de las medidas como el número de cargos de funcionarios y empleados para cumplir las metas. Lo anterior, sin mencionar que para el año 2014 aún no se encontraba en plena aplicación la mencionada Ley 1395.

Pasando al año 2011, el PNDG no varió las apuestas para lograr su meta, lo único que cambió fue el presupuesto para la puesta en marcha, el cual pasó a ser de \$228.841.000.000, representados en la creación de 7.078 cargos, de los cuales 1.177 correspondieron a jueces y magistrados tanto adjuntos como auxiliares (CSJ, 2011, p. 23). En contraste con el año 2010, el órgano administrador de la justicia afirma que existió una reducción cercana al $13 \%$ en los inventarios finales, es decir, que se desacumularon 348.305 procesos. En el Informe presentado por el CSJ al Congreso aparece la siguiente recopilación organizada de los resultados de las medidas de descongestión:

Al iniciar el año 2009, antes de la expedición de la Ley 1285 de 2009, existía en todo el sistema judicial un total de 3.052 .900 procesos represados en inventarios. Sin embargo, gracias a las medidas de descongestión adop- 
tadas con el PNDG, este inventario tuvo una reducción altamente significativa del 26\%, de manera tal que en diciembre de 2011, la cantidad de procesos en inventario ascendió a $2.271 .380,781.520$ procesos menos que en enero de 2009. (CSJ, 2011, p. 23).

En el 2012, a juzgar por el respectivo Informe al Congreso de la República (CSJ, 2012), el PNDG tampoco presentó variaciones sustanciales en las medidas implementadas, pero sí afrontó sucesos que dificultaron su aplicación como la entrada en vigencia de la Ley 1437 de 2011 y el cese de actividades de la Rama que se presentó entre el 11 de octubre y el 10 de diciembre de tal anualidad. Se nombraron 8.431 servidores en los cargos de descongestión, con un costo de \$406.107.000.000 ( $p$. 98), sin que se cumplieran las metas del PNDG, puesto que según dicho texto la evacuación de procesos que se había fijado en 333.622 egresos (p. 97) solo llegó a 223.349, si se resta del inventario inicial -2.532 .621 procesos- el inventario final -2.309 .372 procesos- (p. 100).

\section{2013 y 2014, modificaciones menores y confirmación de pronósticos}

Remitiéndome al desarrollo del PNDG durante el 2013, debo destacar que si bien el cSJ nuevamente se limitó básicamente a crear, modificar, mantener o suprimir cargos de descongestión, en menor medida introdujo algunos cambios de la mano del Plan de Implementación del CGP, tales como la creación de los juzgados de medidas cautelares y la ampliación del número de jueces de ejecución, como se verá cuando desarrolle el capítulo correspondiente.

En 2013, el cS destinó \$741.317.000.000 para nombrar a 10.913 funcionarios y poder eliminar del inventario acumulado 377.414 litigios dejando el monto de procesos acopiados en la cifra de 1.931 .958 (CSJ, 2013, p. 172). Es importante resaltar que en el año en cuestión el funcionamiento de la Rama Judicial, al igual que en periodos anteriores, se vio afectado por los constantes ceses de actividades laborales llevados a cabo en respuesta a los anuncios de suspender o disminuir las labores de descongestión en todo el territorio nacional como consecuencia de la falta de presupuesto.

Tan preocupante se ha tornado el tema presupuestario para los ejecutores de la política de descongestión de despachos, ${ }^{5}$ que ya desde el 2013 anunciaron que la partida asignada con destinación específica al PNDG para los siguientes años era insuficiente, por lo que la perpetuidad de este tipo de medidas en el tiempo está altamente amenazada. ${ }^{6}$ Veamos cuál fue, según el CSJ (2013), el comportamiento de la justicia en el año bajo análisis:

5. El Gobierno apropió para el 2014 el 56\% menos de los recursos solicitados por la Rama Jurisdiccional (CSJ, 2013, p. 179)

6. El monto asignado al PNDG para 2014 corresponde a $\$ 358.000$ millones de pesos, pero este debe ser compartido con la Ley de Tierras y la implementación final de todos los sistemas procesales orales (CSJ, 2013, p. 176). 
En el año 2.013, los 6.029 despachos judiciales del país (de los cuales 1.151 despachos judiciales de descongestión y 4.878 permanentes) recibieron 3.012.046 demandas de Justicia (de las cuales 2.656.779 corresponden a demandas efectivas) y en el mismo año pudieron gestionar 3.272.608 egresos de procesos (de los cuales 2.646.903 corresponden a salidas efectivas de procesos). En 2.013 cada despacho judicial recibió en promedio 504 procesos al año (de los cuales
445 fueron demandas efectivas) y gestionó en promedio 548 procesos al año (de los cuales 443 corresponden a salidas efectivas de procesos). (CSJ, 2013b, p. 184). [Cursivas fuera del texto].

Teniendo claros los tópicos expuestos y en concordancia con los datos previamente reseñados, en la tabla 1 muestro el acumulado de las medias de descongestión puestas en marcha desde 2009 hasta 2013.

Tabla 1. Resumen de las medidas de descongestión emprendidas por el cS desde 2009, valor de estas y resultados en número de egresos

\begin{tabular}{|c|l|c|c|}
\hline Año & Principales medidas & $\begin{array}{c}\text { Valor en pesos } \\
\text { colombianos }\end{array}$ & $\begin{array}{c}\text { Número de egresos } \\
\text { del inventario }\end{array}$ \\
\hline 2009 & $\begin{array}{l}\text { Ley 1285, creación de } \\
\text { cargos transitorios. }\end{array}$ & $\$ 93.947 .000 .000$ & 130.000 \\
\hline 2010 & $\begin{array}{l}\text { Ley 1395, oralidad, crea- } \\
\text { ción de cargos transito- } \\
\text { rios. }\end{array}$ & $\$ 117.301 .148 .000$ & 262.271 \\
\hline 2012 & $\begin{array}{l}\text { Creación de cargos tran- } \\
\text { sitorios. }\end{array}$ & $\$ 228.841 .000 .000$ & 348.305 \\
\hline 2013 & $\begin{array}{l}\text { Creación de cargos tran- } \\
\text { sitorios. } \\
\text { Sitorios, de los despachos } \\
\text { de medidas cautelares } \\
\text { y aumento de jueces de } \\
\text { ejecución. }\end{array}$ & $\$ 406.107 .000 .000$ & 223.349 \\
\hline Total & $\begin{array}{l}\$ 741.317 .000 .000 \\
\text { (1.587.513.148.000 }\end{array}$ & $\mathbf{1 . 3 4 1 . 3 3 9}$ \\
\hline
\end{tabular}

Fuente: elaboración propia a partir de los datos recogidos en la investigación. 
Tabla 2. Resumen del número de vacantes creadas en el marco del PNDG entre 2009 y 2013, discriminando el tipo de cargos instituidos.

\begin{tabular}{|c|c|c|}
\hline Año & $\begin{array}{l}\text { Total de cargos creados } \\
\text { transitoriamente }\end{array}$ & Tipo de cargos transitorios \\
\hline 2009 & 3.790 & $\begin{array}{l}\text { - } 561 \text { jueces y magistrados } \\
\text { - } 3229 \text { empleados }\end{array}$ \\
\hline 2010 & 3.435 & $\begin{array}{l}\text { - } 362 \text { jueces y magistrados } \\
\text { - } 3.073 \text { empleados }\end{array}$ \\
\hline 2011 & 7.078 & $\begin{array}{l}\text { - } 1.177 \text { jueces y magistrados } \\
\text { - } 5.901 \text { empleados }\end{array}$ \\
\hline 2012 & 8431 & - No disponible \\
\hline 2013 & 8060 & $\begin{array}{l}\text { - } 1.136 \text { jueces y magistrados } \\
\text { - } 6929 \text { empleados }\end{array}$ \\
\hline
\end{tabular}

Fuente: elaboración propia a partir de los datos recogidos en la investigación.

Aclarando previamente que no se trata de cifras exactas matemáticamente sino de valores aproximados, las cantidades expuestas me permiten concluir que en cerca de cinco años de aplicación de medidas de descongestión se emplearon más de \$1.587.513.148.000 y se lograron eliminar del inventario final aproximadamente 1.340.000 procesos, es decir, cerca de 265.000 litigios por año en promedio, lo que significa que a la jurisdicción le costó aproximadamente \$1.183.529 eliminar cada proceso del inventario final. Esto quiere decir que de continuar ese ritmo demoraríamos cerca de ocho años en eliminar la totalidad del inventario represado - unos 2.000.000 de procesos aproximadamente-. Sin embargo, según versiones extraoficiales, el presupuesto destinado a descongestión se reducirá a la mitad o incluso desaparecerá (La W, 2014), por lo que eliminar cerca de 265.000 procesos al año se hará muy complejo. Este porvenir se torna aún más grave si pensamos en que en el presente año (2016) entrará en vigencia el CGP, el cual en su artículo 625 obliga que todos los procesos en curso se adapten al nuevo procedimiento dependiendo de la etapa procesal en que se encuentren. En otras palabras, todos los litigios tendrán que ser culminados en audiencia, siempre con presencia del juez, lo que evidentemente disminuirá el índice de 
evacuaciones por la limitación humana y espacial de atender cierto número de audiencias por día y el número limitado de salas disponibles. En consecuencia, la tasa de evacuaciones disminuirá en los próximos años haciendo interminable el problema de la congestión, si seguimos limitados a las políticas hasta ahora empleadas.

Reconocidos procesalistas han argüido posturas similares frente a la relación descongestión-oralidad. Por ejemplo, Miguel Rojas afirma:

Ciertamente el clausulado de la ley 1285 refleja tres propósitos inequívocamente relacionados con el mejoramiento del sistema de justicia: la descongestión judicial, la adopción del sistema procesal oral y la simplificación del acceso a la justicia. La amalgama de los dos primeros propósitos de la forma en que lo plantea la ley, sugiere que la adopción del sistema oral es una herramienta útil para la descongestión judicial, planteamiento cuya inexactitud se evidencia al rompe.

En verdad se trata de dos propósitos claramente independientes y así deberían ser percibidos. De hecho un aparato de justicia congestionado no parece ser un terreno abonado para cultivar las ventajas del sistema oral. (2011, p. 18).

Para confirmar todas las aseveraciones expuestas basta consultar los resultados de las medidas de descongestión puestas en marcha durante el 2014. En el curso de dicha anualidad, según cifras del CSJ (2015), se lograron eliminar del inventario total 233.725 proce- sos (p. 52), esto es, 31.275 menos que los 265.000 estimados anteriormente; el inventario final arrojó 1.698.233 litigios acumulados en la jurisdicción (p. 19); para evacuar los 233.725 procesos fue necesaria la creación o prórroga de 6.564 cargos correspondientes a 737 funcionarios -642 jueces y 95 magistrados- y 5.827 empleados; y un gasto de $\$ 470.424$ millones de pesos (p. 48).

El anterior panorama ha motivado que algunos actores de la administración de justicia se hayan cuestionado sobre lo apropiado de las medidas de descongestión, si estas son examinadas bajo un esquema económico de costo de oportunidad. Surgen entonces algunas preguntas: ¿Valdrá la pena el alto costo de estas medidas?, ¿Existen problemas gerenciales que afectan la efectividad de tales herramientas de contingencia?, ¿Se requerirán mejoras organizacionales y tecnológicas para enfrentar mejor el problema de la congestión?, ¿Por qué motivos el CSJ no implementa medidas alternativas que ayuden a la descongestión del sistema?

En mi concepto y como ya lo he destacado en anteriores apartes, las políticas de descongestión hasta ahora emprendidas no han sido suficientes ni eficientes, como se deduce no solo del número de procesos evacuados, sino del simple análisis costo-beneficio. El PNDG ha sido, lamentablemente, una política pública de alto costo con muy pobres rendimientos que, además, ha sumado problemáticas nuevas a las que ya presentaba la jurisdicción, como es el incremento del $20 \%$ en el tamaño del aparato judicial por cuenta de los aproximadamente 
8.000 funcionarios encargados exclusivamente de las labores de descongestión.

Todo esto debe llevarnos, antes de hacer juicios de valor respecto de la conducta de los miembros de nuestro órgano administrador de la justicia, a reflexionar sobre si lo que se hizo estuvo mal planificado y qué podemos hacer para que ello cambie. Al efecto resulta necesario apelar a la observación de nuevos enfoques del derecho procesal y de ciencias como la ingeniería industrial o la administración de empresas, las cuales Ilevan una amplia ventaja en materia de desarrollo de organizaciones y de optimización de mecanismos de producción y pueden servir como guías para mejorar la eficiencia de la Rama Judicial.

Algunas de las propuestas que nacen del estudio de las citadas ciencias son: mejoras organizacionales mediante la aplicación real de modelos de gestión administrativa; introducción efectiva de nuevas tecnologías como el expediente electrónico y el litigio en línea para evitar que los procesos se queden en el papel, como actualmente está ocurriendo al interior del CSJ; y mejoras en la educación y cultura judicial de todos los actores que conformamos la justicia, en cabeza de la Escuela Judicial Rodrigo Lara Bonilla y de las facultades de Derecho del país.

Expuesta mi posición, invito a los calificados lectores a interiorizar los anteriores planteamientos respecto al panorama de la justicia en Colombia en cuanto al tema de la congestión se refiere, y a analizar si lo que se está hacien- do actualmente en el marco del CGP es de utilidad o no para afrontar la problemática que le dio origen a este texto.

\section{ESTRATEGIAS DEL PLAN DE IMPLEMENTACIÓN DEL CÓDIGO GENERAL DEL PROCESO}

La primera fase del Plan Especial de Descongestión (PED) constaba básicamente de la realización de un censo general de los procesos que cursaban en la jurisdicción ordinaria, es decir, los referidos a conflictos de naturaleza civil, comercial, de familia y agraria. Tal inventario debía estar clasificado por especialidad, tipo, afinidad temática, cuantías, fecha de reparto y estado del trámite procesal, entre otros. En desarrollo de esta fase, el csJ mediante los acuerdos n.os 9695,9705 y 9758 de 18 y 28 de septiembre de 2012 dispuso adelantar el Censo Nacional de Procesos, cuya materialización se vio afectada por el cese de actividades que realizaron los servidores judiciales entre el 11 de octubre y el 10 de diciembre de 2012 (CSJ, 2013a, p. 4).

El objetivo principal de esta actividad, en cuanto a temas de descongestión se refiere, era realizar un diagnóstico de las necesidades específicas y la tipología de las medidas a implantar, con el fin de que el CGP iniciara su actividad con despachos que pudieran manejar el nuevo tipo de proceso por audiencias, sin la carga inmanejable de años atrás. Una vez recopilada la información, esta debía enviarse a la Unidad de Desarrollo y Análisis Estadístico (UDAE), la 
cual obtuvo esencialmente las siguientes conclusiones (CSJ, 2013a, p. 5).

- La mayor carga de procesos es soportada por los jueces civiles municipales, a quienes el CGP les otorgó mayores competencias, por lo que deben adoptarse medidas para aliviar esa mayor carga de trabajo.

- Hay una considerable carga de los juzgados civiles en la etapa de ejecución de la sentencia, la cual debe separarse de las anteriores etapas procesales; dicha fase (ejecución forzada) debe ser asignada a la respectiva oficina de ejecución. La oficina de ejecución, como medida para la descongestión judicial, ha resultado bastante novedosa, dado que busca crear despachos judiciales especializados en etapas procesales, lo cual aligera la labor judicial.

- Se debe generar una nueva situación en la que el juez o magistrado descongestionado quede con una carga razonable de procesos. ${ }^{7}$

En respuesta a lo anterior, las principales formas que el cSJ (2013a, p. 8) encontró razonables para responder al análisis realizado por la UDAE fueron:

1. Prorrogar las medidas de descongestión vigentes, especialmente en cuanto a jueces de aplicación del desistimiento tácito, con el fin de depurar más de 300.000 procesos inactivos.

2. Creación de los juzgados de medidas cautelares y de despachos comisorios.

3. Creación del cargo de jueces de pequeñas causas y competencia múltiple, en aplicación de las leyes 1285 de 2009 y 1395 de 2010, basado en las nociones de acceso a la justicia y de desconcentración de los despachos judiciales.

4. Ampliar el número de jueces de ejecución de sentencias en juzgados municipales y crearlos para juzgados de circuito, responsables de avocar el conocimiento de los procesos desde que queda ejecutoriada la providencia que ordena seguir adelante con la ejecución. Lo anterior, de la mano de la creación de la oficina de ejecución.

5. Crear el cargo de jueces y magistrados itinerantes para que asuman los procesos en los que el término de duración del proceso esté vencido o por vencerse.

Para poner en marcha el PED, la Sala Administrativa del CSJ señaló que se deben cumplir las acciones que se resumen en la tabla 3.

7. Para la justicia colombiana el término carga razonable y su correspondiente equivalencia en número de procesos asignados a cada unidad judicial es aún motivo de estudio por los académicos. Si bien el mismo Consejo Superior de la Judicatura reconoce que aún no existen estudios que determinen cuál es la "carga razonable" para los despachos de la jurisdicción ordinaria, sí fijó algunos lineamientos para el estudio del contenido de tal término (CSJ, 2012, p. 47 a 49 ). 
Tabla 3. Acciones para la implementación del PED para el CGP

\begin{tabular}{|l|l|l|}
\hline Acción & Plazo & Responsable \\
\hline $\begin{array}{l}\text { Recopilar información del in- } \\
\text { ventario general de procesos }\end{array}$ & 8 de marzo de 2013 & UDAE \\
\hline $\begin{array}{l}\text { Integrar, valorar y analizar in- } \\
\text { ventario real de procesos }\end{array}$ & 14 de mayo de 2013 & UDAE \\
\hline $\begin{array}{l}\text { Diseño del Plan Nacional de } \\
\text { Descongestión }\end{array}$ & 21 de junio de 2013 & $\begin{array}{l}\text { Sala Administrativa CSJ y } \\
\text { UDAE }\end{array}$ \\
\hline $\begin{array}{l}\text { Elaborar proyecto de acuerdo } \\
\text { de descongestión }\end{array}$ & 28 de junio de 2013 & UDAE \\
\hline $\begin{array}{l}\text { Socialización plan de descon- } \\
\text { gestión }\end{array}$ & 31 de junio de 2013 & $\begin{array}{l}\text { UDAE y Sala Administrativa } \\
\text { CSJ }\end{array}$ \\
\hline $\begin{array}{l}\text { Ajustes de plan de descon- } \\
\text { gestión }\end{array}$ & 9 de agosto de 2013 & UDAE \\
\hline $\begin{array}{l}\text { Aprobación acuerdo de plan } \\
\text { de descongestión }\end{array}$ & 30 de agosto de 2013 & Sala Administrativa CSJ \\
\hline $\begin{array}{l}\text { Ejecución plan de desconges- } \\
\text { tión }\end{array}$ & $\begin{array}{l}\text { Del } 30 \text { de agosto de 2013 al } \\
31 \text { de diciembre de 2016 }\end{array}$ & $\begin{array}{l}\text { Sala Administrativa CSJ, } \\
\text { UDAE, Infraestructura e Infor- } \\
\text { mática. }\end{array}$ \\
\hline
\end{tabular}

Fuente: elaboración propia con base en Consejo Superior de la Judicatura. Sala Administrativa (2013).

Para constatar cuáles de las estrategias fijadas por el cS para hacer frente al diagnóstico brindado se han puesto en marcha, a continuación prosigo con una relación sucinta de los acuerdos emanados de la Sala Administrativa de dicho organismo durante los años 2012, 2013 y 2014.

1. Acuerdo No. PSAA $12-9695$ de septiembre 18 de 2012: "Por el cual se crean algunos cargos transitoriamente para apoyar la rea- lización del inventario de procesos a que hace referencia la Ley 1564 de 2012 artículo 618 (CGP)".

2. Acuerdo No. PSAA $13-9810$ del 11 de enero de 2013: "Por el cual se adoptó el plan de acción para la implementación del Código General del Proceso".

3. Acuerdo No. PSAA 13-9927 del 6 de junio de 2013: "Por el cual se aprueban los ajus- 
tes al plan de acción para la implementación del CGP".

4. Acuerdo No. PSAA 13-9962 del 31 de julio de 2013: "Por el cual se ajustan y adoptan medidas de descongestión". Los principales ajustes y nuevas medidas adoptadas son las siguientes: 1) se suprimen todos los jueces adjuntos; ; 2) transformación de jueces adjuntos municipales con funciones piloto en juzgados civiles municipales; 3) creación de juzgados civiles de circuito de descongestión, promiscuos del circuito de descongestión, municipales de descongestión y promiscuos municipales (transitorio); 7) creación de juzgados y oficinas de ejecución civil circuito y municipal (transitorias).

5. Acuerdo No. PSAA $13-9979$ del 30 de agosto de 2013: "Por el cual se adoptan unas medidas para la aplicación del desistimiento tácito y la exclusión de inventarios".

6. Acuerdo No. PSAA 13-9984 del 5 de septiembre de 2013: "Por el cual se reglamentan los Juzgados de Ejecución Civil, Ejecución en asuntos de Familia, de menor y mínima cuantía y se adoptan otras disposiciones". Tanto a nivel municipal como de circuito se crean los juzgados de menor y mínima cuantía por medio de la conversión de antiguos juzgados civiles municipales, se crean las oficinas de ejecución, se prorrogan los despachos civiles de descongestión y se adoptan otras disposiciones.

7. Acuerdo No. PSAA 13-9991 del 26 de septiembre de 2013: "Por el cual se recopilan, ajustan y adoptan medidas de descongestión". Por ser el principal acuerdo en cuanto a medidas para descongestionar realizaré una breve descripción de sus puntos más importantes en lo referente a la jurisdicción ordinaria: 1) Fortalecimiento de la creación de jueces de pequeñas causas en civil y laboral; 2) los despachos de descongestión no recibirán acciones constitucionales; el cumplimiento de metas se vuelve obligatorio; 3) se fijan metas de sentencias y autos, para jueces y magistrados en todas las jurisdicciones (sin incluir a las altas Cortes) y se especifica qué tipo de estas providencias sirven para alcanzar metas -muy altas desde mi concepción-; 4) se prorrogan varios cargos de funcionarios creados anteriormente para ciertos despachos en descongestión; 5) se crean oficinas de ejecución en asuntos de familia; 7) se trasforman algunos juzgados antiguos de descongestión en juzgados de mínima cuantía y en juzgados de ejecución. Dichas medidas estarían vigentes hasta el 19 de diciembre de 2013.

8. Los jueces adjuntos son servidores judiciales de descongestión, como lo menciona el artículo cinco del Acuerdo n. ${ }^{\circ}$ PSAA129781 (diciembre 18 de 2012); tienen funciones semejantes a las de los jueces de descongestión, trabajan en el mismo lugar de un juez titular y tienen facultad para nombrar un sustanciador y un escribiente. 
8. Acuerdo No. PSAA 13-10071 del 27 de diciembre de 2013: "Por el cual se implementa el modelo procesal de la oralidad". A través de este acuerdo se dividen los distritos judiciales del país en grupos que implementarán la oralidad de manera paulatina.

9. Acuerdo No. PSAA $13-10073$ del 27 de diciembre de 2013: "Por el cual se adoptan unas medidas de descongestión en el territorio nacional". En él se fijan los objetivos del PED, las políticas a emprender y las estrategias para su ejecución; 2) la distribución de los distintos despachos entre orales y escritos en varias ciudades del país; y 3) se crean, modifican y eliminan juzgados en varias especialidades de la jurisdicción.

10. Acuerdo No. PSAA 13-10073 del 27 de diciembre de 2013: "Por el cual se reglamenta la gradualidad para la implementación del Código General del Proceso".

11. Acuerdo No. PSAA 14-10155 del 28 de mayo de 2014: "Por el cual se suspende el cronograma previsto en el Acuerdo PSA1310073 del 27 de diciembre de 2013". Se trata del cronograma de implementación del CGP previsto en el artículo 1, cuya suspensión aplica hasta tanto el Gobierno Nacional apropie los recursos indispensables.

12. Acuerdo No. PSAA 14-10195 del 31 de julio de 2014: "Por el cual se recopilan, ajustan y adoptan unas medidas de descongestión". Se fijan varias políticas como: 1) los juzgados beneficiados con medida de descongestión deberán incrementar el nivel de egreso efectivo en un $25 \%$, con respecto al periodo inmediatamente anterior a su creación; 2) se modifican las metas de evacuación de los despachos por especialidad y, finalmente, se prorrogan, crean y suprimen despachos de descongestión en todo el país de acuerdo con la disponibilidad presupuestal.

13. Acuerdo No. PSAA 14-10197 del 5 de agosto de 2014: "Por el cual se adoptan unas medidas de descongestión". Este acuerdo prolongó las medidas de descongestión en la jurisdicción hasta noviembre 31 de 2014 , ya que el ejecutivo solo giró $\$ 170$ mil millones en lugar de los $\$ 250.000$ millones que pedía el cSJ.

14. Acuerdo No. PSAA14-10251 del 14 de noviembre de 2014: "Por el cual se prorrogan, ajustan y adoptan unas medidas de descongestión". A través de la inversión de \$50.534.290.241 se pudieron prorrogar las medidas y se establecieron nuevas metas, por ejemplo, un juzgado civil municipal de mínima cuantía debe proferir cincuenta sentencias al mes y uno promiscuo municipal treinta.

Teniendo en cuenta el contenido de los acuerdos citados y las fechas de adopción es fácil constatar que el cronograma del PED fue quebrantado en todas sus etapas. No obstante, debe reconocerse que para finales del año 2013 e inicios del 2014 el cs implementó cier- 
tas medidas que aunque pueden contribuir a la solución del problema sub examine, persisten vacíos que pasaré a detallar.

En primer lugar, si bien la reglamentación de los juzgados de ejecución civiles y de familia y la creación de las oficinas de ejecución son vistas con buenos ojos, no sucede lo mismo respecto de la conversión de algunos de los antiguos juzgados civiles municipales de descongestión en juzgados de descongestión de menor o de mínima cuantía, por cuanto se le dio prelación a los de menor cuantía sin tener en cuenta el aumento del volumen de los procesos de mínima cuantía, incremento ocasionado por la modificación que introdujo el CGP de dicho factor objetivo para la determinación de la competencia. Ejemplo de ello es Bogotá, donde el CS ordenó transformar 55 juzgados de descongestión en despachos de menor cuantía y solo 50 en de mínima cuantía. Es decir, la entidad judicial, en su búsqueda de eficiencia a través de la especialización de funciones, ignoró las necesidades reales de la jurisdicción creando más juzgados de menor cuantía en lugar de preferir a los de mínima cuantía, lo que claramente no está acorde con el nuevo escenario litigioso del país, como lo diagnosticó la UDAE.

Otro punto importante que debo señalar en cuanto a la conversión de despachos consis- te en la capacitación o información que debe brindarse a los usuarios sobre los nuevos cambios en las especialidades de los juzgados, con el fin de evitarles traumatismos por desconocimiento del paradero de sus procesos. Ello sin mencionar los retrasos derivados del desgaste de los funcionarios y de la gestión por cuenta del traslado de los expedientes a los nuevos despachos.

Respecto de los posibles resultados de estas medidas es importante recordar que fueron proferidas a finales de 2013 y apenas están entrando progresivamente en funcionamiento, puesto que su inicio está condicionado a la disponibilidad de infraestructura física en los palacios de justicia seccionales. Adicionalmente, el reparto de procesos a los nuevos despachos también ha sido lento, al igual que los nombramientos de los funcionarios que ejercerán los cargos, por lo que es imposible que sus avances cumplan la "carga razonable de trabajo" 9 (400 procesos para los juzgados de menor cuantía y 1000 para los de mínima cuantía) y las metas mensuales de sentencias (30 para los de mínima y menor cuantía y 80 para los de ejecución) se puedan ver reflejadas con prontitud, especialmente si antes de iniciar con la sustanciación de fondo de los litigios que se les asignaron estos despachos deben reorganizar sus agendas y realizar el estudio de factibilidad.

9. Si bien el mismo Consejo Superior de la Judicatura (2012c, pp. 47-49) reconoce que aún no existen estudios que determinen cuál es la "carga razonable" para los despachos de jurisdicción ordinaria, sí fijó algunos lineamientos para el estudio del contenido de tal término. 
Otro de los problemas es la poca articulación entre las ramas del Poder Público, tan necesaria para lograr un desarrollo que permita conseguir el fin común de garantizar a todos los colombianos el derecho de acceso a la justicia. Este cuestionamiento se basa principalmente en las inconformidades mutuas provenientes tanto de los miembros de la Rama Judicial como del Gobierno. Veamos: el csJ arguye que el retraso en la puesta en marcha de la Ley 1395 de 2010 y del CGP se debe a que el Ejecutivo no ha asignado los recursos necesarios para la construcción de la infraestructura requerida, la capacitación de los funcionarios y en general para la obtención de todo lo ineludible para cumplir el objetivo antes mencionado (Ávila Palacios, 2012). Esta problemática fue expuesta por el CSJ en la parte considerativa del Acuerdo PSAA 14-10155 del 27 de mayo de 2014 "Por el cual se suspende el cronograma previsto en el Acuerdo PSA13-10073 del 27 de diciembre de 2013":

Que el artículo 627, numeral 6, de la Ley 1564 de 2012, establece que el Consejo Superior de la Judicatura determina la gradualidad de la implementación del Código General de Proceso, en la medida en que se ejecuten los programas de formación de funcionarios y empleados y se disponga de la infraestructura física y tecnológica, del número de despachos judiciales requeridos para el funcionamiento del proceso oral y por audiencias. (Párr. 2).

Que no se han apropiado por el Gobierno Nacional los recursos necesarios para las acti- vidades mencionadas, ni para la continuidad de las medidas de descongestión... (párr. 4).

Que el Gobierno Nacional ofreció la disposición de dos (2) billones de pesos para la ejecución de diferentes programas, recursos respecto de los cuales no se cuenta aún con apropiaciones concretas. (Párr. 5). [Cursivas fuera del texto original].

Como es evidente, la falta de colaboración armónica entre las ramas del Estado colombiano, en cuanto a la política de descongestión se refiere, ha generado que la implementación de las medidas tendientes a la oralidad se haya prácticamente petrificado en el tiempo, como consecuencia de la suspensión del cronograma de ejecución del CGP ordenada en el artículo primero del Acuerdo en comento, "hasta tanto el Gobierno Nacional apropie los recursos indispensables y que fueron solicitados, para su entrada en vigencia".

Contrario a lo argumentado por el CSJ, el Ejecutivo se defiende arguyendo que sí existen los recursos para el desarrollo de los planes de implementación, y que la mayoría de problemas en la consumación de estas nuevas disposiciones normativas y de los programas que las acompañan se debe a la pobre administración del CSJ de dichos recursos así como a la poca diligencia de los miembros que conforman tal cuerpo colegiado para ejecutar las políticas públicas aquí analizadas (Reyes, 2014). De acuerdo con tal tesis el Gobierno propuso, en el acto legislativo conocido como "equilibrio de poderes", la eliminación del órgano administrador de la Rama Jurisdic- 
cional y como alternativa planteó la creación del Sistema Nacional de Gobierno y Administración Judicial (Redacción Política, 2014).

Todo lo reseñado, más allá de los debates políticos e ideológicos que rodean la administración del Poder Judicial en nuestro país, debe hacernos reflexionar respecto de la dificultad existente en los distintos niveles organizacionales del Estado para lograr el correcto desarrollo de la política pública de descongestión y tratar de responder por qué ha sido tan complejo alcanzar las metas de evacuación de procesos y cuáles pueden ser algunas alternativas de solución adecuadas.

Para aclarar más estas situaciones continuaré con un análisis de los principales problemas que, a mi juicio, surgen de las medidas de descongestión previamente expuestas y algunas posibles alternativas de solución.

\section{EVENTUALES PROBLEMAS DE LAS MEDIDAS ADOPTADAS EN COLOMBIA}

\section{A) escogencia de jueces de descongestión y su "atrincheramiento"}

Frente la prórroga en los cargos de jueces y magistrados de descongestión debo manifestar mi oposición a que se continúe con la es- cogencia "a dedo" empleada en la actualidad, pues si bien se convoca primero a los candidatos de la lista de elegibles resultante del último curso concurso realizado por la Escuela Judicial Rodrigo Lara Bonilla, en la mayoría de Ios casos estos no aceptan el nombramiento por no satisfacer sus requerimientos de estabilidad laboral o de ubicación física del cargo a proveer, lo que lleva a que se nombren los empleados de los juzgados de descongestión arbitrariamente y, por tanto, no siempre tengan las calidades exigidas para cumplir satisfactoriamente su labor.

Como solución alternativa propongo que se acojan métodos exitosos extraídos del derecho foráneo, por ejemplo, de Uruguay, Chile y Estados Unidos, ${ }^{10}$ donde el órgano de administración judicial para realizar las labores de descongestión y garantizar la idoneidad del personal contrató jueces recién pensionados, con amplia experiencia, que pueden ser designados en las regiones en que solían ejercer su labor, y dejó los jueces ordinarios solo conociendo las nuevas demandas (Piñeros, 2011). Con el anterior "tratamiento de choque-operativo" se vieron resultados positivos en los estados de California y Florida (EE. UU.); en este último estado se logró culminar un número de 65.830 procesos de quiebra durante junio-julio de 2010 y para el primer semestre de 2011 esperaban evacuar 140.000 procesos (Clavijo, 2011, p. 53). Otra bondad es que permite

10. En los estados de Florida y California, en Estados Unidos, se contrataron jueces pensionados teniendo como resultado cifras exitosas de evacuación (Clavijo, 2011, p. 52). 
contrarrestar el riesgo de burocratización que el nombramiento "a dedo" puede ocasionar, y que en Brasil ha dificultado ver resultados eficientes y a corto plazo (Clavijo, 2011, p. 53). ${ }^{11}$

Expertos como el profesor Diego López Medina han expuesto otra desventaja del nombramiento masivo de empleados de descongestión: el posible "atrincheramiento" de los funcionarios encargados de esta labor. Otras voces han señalado que va a ser muy difícil por razones políticas y laborales no continuar con los servicios de estos trabajadores una vez finalicen las labores transitorias. Al efecto se propuso un estudio que según la ex ministra de Justicia, Ruth Stella Correa, “permitirá determinar cuántos funcionarios de descongestión se requieren para evacuar los miles de procesos que se encuentran represados y además definir cuáles de esos cargos podrán ser permanentes" (citada por Redacción Justicia, 2013).

También es necesario agregar que la destinación de recursos humanos a instituciones mal diseñadas, con grandes problemas de eficacia, una dinámica de trabajo lenta y sin los resultados esperados, deben tenerse en cuenta a la hora de evaluar el desarrollo de la justicia colombiana. Es por eso que sostengo que el problema no solo radica en el número de funcionarios disponibles para atender los requerimientos de los usuarios de la justicia, también deben evaluarse los aspectos propios de las metodologías de trabajo que se implementan, pues la simple relación a más trabajadores mayor productividad es claramente equivocada.

En otros términos, el problema radica en que no basta con volver permanentes los jueces de descongestión para solucionar los problemas de la Rama Judicial en materia de evacuación de procesos; hay que considerar el lastre o las dinámicas inoperantes de trabajo que vienen haciendo curso en la jurisdicción y que impiden su labor eficiente. De ahí la propuesta de implantar macropolíticas encaminadas a incrementar la eficiencia de la justicia, entendida esta como una organización que se asemeja a una empresa en la cual resultan indicadas estrategias como: 1. Mejoras organizacionales, es decir, adopción de modelos de gestión administrativa; 2 . Introducción efectiva de nuevas tecnologías como el expediente electrónico y el litigio en línea; 3. Incremento de la calidad en la educación y la cultura judicial de todos los actores que conformamos la justicia, en cabeza de la Escuela Judicial Rodrigo Lara Bonilla y de las facultades de Derecho del país.

Como evidencia de la conversión de ciertos despachos judiciales en permanentes a pesar de que seguirán con el lastre organizacional antes expuesto, puedo citar el Acuerdo N. ${ }^{\circ}$ PSAA 13-9991, el cual convierte algunos despachos antes dedicados a la descongestión en juzgados de mínima y menor cuantía. También

11. Vale la pena mencionar que si bien la problemática del estado de Florida tuvo un origen coyuntural como fue la crisis inmobiliaria, su estrategia puede ser útil para la solución de los problemas estructurales de nuestro sistema judicial, o al menos para evacuar los procesos represados al momento de entrar en vigencia el CGP. 
es factible constatar que la Comisión del Plan de Implementación del CGP propuso convertir en permanentes algunos despachos transitorios de las principales ciudades del país, como los juzgados de descongestión para medidas cautelares y despachos comisorios (CSJ Acción, 2012, p. 8). Cabe preguntarse, entonces, si este es el inicio de la transformación en permanentes de los cargos de descongestión (Colprensa, 2013).

De otra mano, otros expertos aducen, con razón, que la conversión en permanentes de tales cargos es una erogación fiscal demasiado alta que la Rama Judicial no podrá soportar, lo que llevó al Ministerio de Hacienda junto a la entonces ministra de Justicia a plantear la realización de estudios de viabilidad de tal propuesta.

De acuerdo con lo previo, considero que precisamente por el método de escogencia del personal de descongestión, tornar a estos funcionarios en permanentes no garantiza su idoneidad y, por tanto, no se estaría cumpliendo con el objetivo de mejorar el nivel de eficiencia de la Rama Judicial. Por ello, en mi opinión, debe seguirse utilizando el curso concurso de la Escuela Judicial Rodrigo Lara Bonilla al momento de proveer un cargo que pase de transitorio a permanente, con el fin de garantizar la estabilidad laboral del empleado y que este no rechazará el cargo por cuestiones de ubicación geográfica.

En complemento a lo reseñado, y especialmente frente a la problemática del atrinchera- miento de los funcionarios de descongestión, es necesario recalcar un problema recurrente cada cuatro meses en nuestra administración de justicia: los paros laborales. Como es de público conocimiento, desde finales de 2013 se han presentado varias parálisis de la Rama Jurisdiccional como consecuencia de la alteración o eliminación masiva de cargos de descongestión (Jiménez, 2014); ello, junto a los reclamos por las condiciones laborales (Caracol Radio, 2014), son los principales motivos de freno total de las labores judiciales en nuestro país. Frente al tema en cuestión, la abogada y columnista Mariela Vega de Herrera (s.f.) ha expresado su preocupación por las condiciones de estos empleados y respecto a su "transitoriedad":

No obstante que por disposición constitucional los empleos públicos por regla general son de carrera, con estabilidad relativa y excepcionalmente de libre nombramiento y remoción, cuando se trata de servidores judiciales de descongestión las normas sobre carrera judicial no aplican a cabalidad; tanto la creación, ubicación, distribución y reducción de cargos corresponden en buena parte a criterios subjetivos del CSJ.

Creadas así las condiciones para que estos despachos sean determinantes en el funcionamiento de la justicia, eliminarlos de manera repentina causaría una parálisis del servicio. (...) Conclusión de lo ocurrido y remedio a la crítica situación debería ser la inmediata puesta en marcha de una política eficaz encaminada a la reforma a la justicia. [Énfasis fuera del texto]. 
Como se evidenció, el tema expuesto no puede ser considerado un mal menor, pues paralizar frecuentemente las actividades de la justicia más allá de negar la prestación de un servicio público configura una de las mayores violaciones a los derechos de acceso a esta y a la dignidad del ser humano (CConst., C-334/2012, M. González) que, como no pueden ser objeto de discusión, son totalmente inadmisibles en el marco de un Estado social y democrático de derecho como el nuestro (CConst., C-100/2001, M. Sáchica). En otras palabras, la paradoja que se materializa en el caso concreto consiste en que el "órgano garantista de los derechos" y frente al cual creamos la política de descongestión como herramienta encaminada a ampliar la protección de estos, se ha convertido en el mayor transgresor de dichos principios fundamentales, lo cual es inaceptable y debe ser corregido en el menor término posible, so pena de seguir incentivando las soluciones extrajudiciales para los problemas del diario vivir de todos los colombianos.

\section{B. Exigencia de metas e incentivos pecuniarios por aumento en la productividad}

Otra crítica importante al CSJ es su errónea creencia de que la extensión del tiempo de funcionamiento de los despachos transitorios es la mejor herramienta para descongestionar el sistema de una manera real y significativa, cuando la experiencia ha demostrado que los despachos de descongestión en realidad causan un daño mayor que el que alivian. Tal tesis, expuesta por autores como Leonardo Torres Calderón (2002) ${ }^{12}$ se fundamenta en que exigir un alto número de fallos mensuales a los jueces de descongestión genera sentencias con poca calidad, que en lugar de ponerle fin a los conflictos producen un aumento en el número de apelaciones, congestionando así los despachos de los superiores de los funcionarios que profirieron el pronunciamiento inicial.

Actualmente, dentro de la jurisdicción, a los funcionarios de descongestión se les exige producir treinta fallos por mes (CSJ, Ac. PSAA139991, 2013), cifra muy por encima de la capacidad y calidad que requiere este tipo de trabajo y que según Torres (2002, p. 62) está entre 10 y 20 fallos, teniendo en cuenta que los procesos que se les asignan implican controversias complejas que el juez de conocimiento titular muchas veces delega por su alto grado de dificultad. Lo anterior sin mencionar la posibilidad de los agraviados de interponer acciones como la tutela, que también entrarían a incrementar el volumen de expedientes que cursan en los juzgados y que acaparan por lo menos el $50 \%$ del tiempo del trabajo del Tribunal donde se encuentren, ya que en promedio cada despacho tiene a su cargo de tres a cinco

12. El autor expone que en el caso de la jurisdicción contenciosa administrativa se exigían 24 fallos mensuales a los jueces de descongestión. 
acciones constitucionales por semana (Torres, 2002, p. 61).

La misma consideración sobre las metas mensuales demasiado altas puede aplicarse a otras propuestas traídas de sistemas como el español y el chileno, consistentes en la necesidad de fijar incentivos pecuniarios a los jueces para aumentar su productividad y, por ende, el número de egresos anuales de cada despacho judicial (Santos, 2005, p. 6). Concuerdo parcialmente con dicha crítica porque si bien esta propuesta podría funcionar eventualmente en nuestro país, debe manejarse con gran cautela teniendo en cuenta que muchas veces los indicadores pueden ser manipulados con la finalidad de mostrar resultados positivos. Como un ejemplo de lo anterior puede citarse lo ocurrido en España en 2003, cuando para poder definir las recompensas pecuniarias que cada juez debía recibir se introdujo un sistema de medición de desempeño, en el que se evidenció que expedientes que antes se acumulaban dejaron de hacerlo sin explicación, o causas que se solían solucionar por autos pasaron a resolverse por medio de sentencias en razón a que estas tienen mayor valor en dicha medición (Pastor, 2005, p. 18).

Frente a este tema considero viable la propuesta de instituir eventualmente incentivos pecuniarios por producción a los funcionarios judiciales colombianos, con la condición de que la productividad del juez se evalúe teniendo en cuenta no solo el número de sentencias emitidas sino el aspecto cualitativo de dichas decisiones. Lo anterior puede constatarse a través de estadísticas sobre el número de fallos confirmados o revocados por el superior funcional del despacho que emitió el pronunciamiento de fondo.

\section{La experiencia del Nuevo Código de Procedimiento Administrativo y de lo Contencioso Administrativo: la división de despachos}

La Ley 1437 de 2011 derogó el antiguo Decreto 01 de 1984 y en su lugar introdujo el proceso por audiencias en la jurisdicción contenciosa administrativa. Esta norma, que lleva cerca de cuatro años de vigencia, nos permite evaluar su principal medida para enfrentar la congestión y contrastarla con el tránsito de legislación del CGP. El tema que quiero observar es la exitosa división que se hizo de los despachos administrativos permanentes para la puesta en marcha de la oralidad.

La mencionada división obedeció a lo anotado por el CSJ de la mano del Consejo de Estado, respecto a que la oralidad no podía iniciar con despachos congestionados. Por eso, al momento de tramitar esta nueva ley, el máximo Tribunal de lo Contencioso Administrativo propuso en el artículo 304 del CPACA:

El Consejo Superior de la Judicatura con la participación del Consejo de Estado, preparará y adoptará, entre otras medidas transitorias, un Plan Especial de Descongestión de la Jurisdicción de lo Contencioso Administrativo, cuyo objetivo es el de llevar hasta 
su terminación todos los procesos judiciales promovidos antes de la entrada en vigencia de la presente ley y que se encuentren acumulados en los juzgados y tribunales administrativos y en el Consejo de Estado. [Cursivas fuera del texto].

El reconocer la importancia de que los despachos iniciaran el trámite de la oralidad con carga cero conllevó la división de las unidades judiciales existentes en aquellas que seguirían con el sistema escritural hasta finalizar la totalidad del inventario acumulado, apoyadas por los cargos de descongestión, y las que comenzarían a conocer procesos de acuerdo con el nuevo código. Para comprobar las anteriores conclusiones es pertinente mostrar las cifras de evacuación registradas por el csJ en su Informe al Congreso de la República (2013b, p. 48):

A 31 de diciembre de 2012, el inventario final de los asuntos del antiguo sistema era de 195.798, logrando disminuir este inventario en el año 2013 a 121.969, lo que representa una reducción del 37,7\%, es importante señalar que los Tribunales Administrativos aún siguen recibiendo procesos del sistema escrito, toda vez que la evacuación de procesos a nivel de juzgados incide en la segunda instancia por apelación. [Cursivas fuera del texto].

Esta buena medida, que en mi opinión sería idealmente replicable en la jurisdicción civil puesto que está funcionando adecuadamente en la actualidad, lamentablemente no puede hacerse por cuanto el régimen de transición legislativa que el CGP determinó en su artículo 625 ordena que todos los procesos, dependiendo de la etapa procesal en que se encuentren, deben adaptarse a la oralidad. Para replicar la división de despachos del CPACA sería necesario modificar el régimen de transición del CGP.

No obstante los argumentos expresados en favor de la división de despachos introducida por el CPACA debo destacar una problemática a la que se han visto enfrentados los magistrados del Consejo de Estado y en general los usuarios de esta especialidad de la jurisdicción al momento de proferir sentencia en los nuevos procesos orales. Como es bien sabido, la división de despachos según el sistema escritural y el oral se implementó solo en los juzgados y tribunales, por ello un Consejero de Estado conoce actualmente tanto de procesos escritos como de controversias orales. La dificultad radica, entonces, en la necesidad de irrespetar los turnos para fallo que ya están asignados, debido a la mayor celeridad de un litigio tramitado por audiencias sobre otro del antiguo sistema escritural. Ello suscita un problema jurídico que aun el mismo Consejo de Estado no ha podido resolver por la diferencia de criterios existente entre los miembros del citado cuerpo colegiado. Mientras algunos magistrados esgrimen que los turnos ya fijados a los procesos del sistema escrito son inalterables y, por ello, los nuevos litigios orales tendrán que esperar varios años en los anaqueles hasta que se agoten todos los turnos ya asignados, otros consideran un absurdo jurídico congelar las decisiones del nuevo sistema por audiencias, pues se 
incumpliría con el sentido teleológico de dicha reforma y no se ayudaría en nada a solucionar el problema de la congestión judicial. De acuerdo con la última postura, se tendría que adoptar un sistema mixto de turnos para sentencia que les permita a los consejeros llevar a las Salas de Decisión un proceso escrito y luego uno oral. Esta sería, en mi concepto, la postura más acertada desde el punto de vista sustancial, dado que aplica criterios como el del efecto útil de las normas y permite garantizar adecuadamente derechos como la tutela judicial efectiva, al privilegiar la eficiencia.

\section{CONCLUSIONES}

Debo señalar como presupuesto inicial a estas conclusiones, que si bien las cifras expuestas por el CSJ en los distintos informes al Congreso de la República no son homogéneas y por tanto su confiabilidad podría ser cuestionada, sí permiten algunas reflexiones y suscitan preocupaciones respecto al proceso de implementación de la "nueva" justicia ordinaria, que directamente impactan el tema de la congestión judicial. De otra parte, reitero que la intención de este escrito no es desacreditar los esfuerzos emprendidos por todos los operadores judiciales en cuanto a temas de descongestión se refiere, sino, por el contrario, colaborar en lo posible en el mejoramiento del derecho de acceso a la justicia que cobija a todos los colombianos.

Entre el año 2009 y el 2012 las medidas de descongestión se concentraron en la creación de juzgados de descongestión adjuntos y de apoyo, el nombramiento de funcionarios provisionales y aplicación de la perención y el desistimiento tácito. No fue hasta 2013 que sobrevino un cambio, fruto del poco éxito de las políticas antes mencionadas, pues en cerca de cinco años de aplicación de medidas de descongestión se han empleado más de $\$ 1.587 .513 .148 .000$ y se ha logrado eliminar del inventario final aproximadamente 1.340.000 procesos, es decir, un promedio de 265.000 procesos por año que le significan a la jurisdicción aproximadamente \$ 1.183.529 millones de pesos por cada proceso eliminado del inventario final. De continuar dicha tendencia demoraríamos más de ocho años en eliminar la totalidad del inventario represado, esto es, 1.600.000 procesos aproximadamente. Lo anteriormente expuesto genera gran preocupación teniendo en cuenta que en el próximo año inicia la aplicación del CGP en el territorio nacional, y con ello todos los procesos en curso en litigios por audiencias requerirán siempre la presencia del juez en las actuaciones, lo que eventualmente podrá traer como consecuencia una reducción en la tasa de evacuación de procesos de cada unidad judicial.

También se han presentado múltiples inconvenientes en cuanto al cumplimiento del cronograma del Plan de Implementación del CGP y del PED para el mismo estatuto procesal civil. Ello dificulta la labor de diagnóstico respecto de las nuevas medidas adoptadas durante los años 2013 y 2014, pues las cifras de desempeño arrojadas por los operadores judiciales no reflejan eficiencia en la puesta en marcha de la totalidad de tales medidas. 
Otra preocupación tiene que ver con la aplicación de ciertos métodos de escogencia de funcionarios transitorios, que si bien en el papel aparentan ser objetivos -oportunidad de copar las vacantes a partir de las listas de elegibles extraídas del curso concurso-, por realidades empíricas se ha diagnosticado que termina siendo una selección a gusto de los electores. Por lo dicho se recomienda estudiar experiencias como las de Chile, Estados Unidos y Uruguay, que pueden llegar a ser alternativas interesantes de solución a la problemática expuesta.

Otra modificación que considero relevante estudiar junto a la del método de nombramiento de funcionarios judiciales transitorios es la del tránsito de legislación consagrado en el artículo 625 del CGP, el cual ordena que todos los procesos actualmente en curso, regidos por el procedimiento civil anterior, se adapten al CGP dependiendo de la etapa procesal que se encuentren. Como alternativa encuentro más interesante revisar el modelo implementado por el CPACA, ya que permite que el proceso por audiencias se tramite en juzgados con carga inicial cero.

Finalmente, debo afirmar que todas estas medidas serán insuficientes para acabar con la congestión del sistema judicial colombiano de no ir reforzadas con otras como la implementación del litigio en línea, a través del uso del expediente electrónico, tal cual lo han propuesto en España (Ministerio de Justicia, 2011) y Nicaragua (Unión Europea, 2006), por ejemplo, o que se repliquen experiencias que han sido de gran utilidad en otras áreas y que ya están siendo estudiadas en nuestro país, como la elaboración de modelos de gestión para la administración eficiente de justicia, los cuales parten de ejercicios piloto como los iniciados en Itagüí y Envigado, departamento de Antioquia. En otras palabras, nuestra administración de justicia no puede continuar con el ritmo actual. Todos los que interactuamos en el marco de la jurisdicción debemos poner de nuestra parte para introducir mejoras gerenciales, culturales, tecnológicas y organizacionales que permitan a nuestra justicia enfrentar el colapso que eventualmente se avecina.

\section{Referencias}

1. Acuerdo No. PSAA-12-9695 [Consejo Superior de la Judicatura]. Por el cual se crean algunos cargos transitoriamente para apoyar la realización del inventario de procesos a que hace referencia la Ley 1564 de 2012. Septiembre 8 de 2012.

2. Acuerdo No. PSAA-13-9810 [Consejo Superior de la Judicatura]. Por el cual se adopta el Plan de Acción para la Implementación del Código General del Proceso. Enero 11 de 2013.

3. Acuerdo No. PSAA-13-9927 [Consejo Superior de la Judicatura]. Por el cual se aprueban los ajustes al Plan de Acción para la Implementación del Código General del Proceso. Junio 6 de 2013. 
4. Acuerdo No. PSAA-13-9962 [Consejo Superior de la Judicatura]. Por el cual se ajustan y adoptan unas medidas de descongestión. Julio 31 de 2013.

5. Acuerdo No. PSAA-13-9979 [Consejo Superior de la Judicatura]. Por el cual se adoptan unas medidas para la aplicación del desistimiento tácito y la exclusión de inventarios en asuntos de carácter civil, comercial, de familia y agrario. Agosto 30 de 2013.

6. Acuerdo No. PSAA-13-9984 [Consejo Superior de la Judicatura]. Por el cual se reglamentan los Juzgados de Ejecución Civil, Ejecución en asuntos de Familia, de menor y mínima cuantía y se adoptan otras disposiciones. Septiembre 5 de 2013.

7. Acuerdo No. PSAA-13-9991 [Consejo Superior de la Judicatura]. Por el cual se recopilan, ajustan y adoptan unas medidas de descongestión. Septiembre 26 de 2013.

8. Acuerdo No. PSAA-1310071 [Consejo Superior de la Judicatura]. Por el cual se implementa el modelo procesal de la oralidad. Diciembre 27 de 2013.

9. Acuerdo No. PSAA-13-10073 [Consejo Superior de la Judicatura]. Por el cual se reglamenta la gradualidad para la implementación del Código General del Proceso. Diciembre 27 de 2013.

10. Acuerdo No. PSAA 14-10155 [Consejo Superior de la Judicatura]. Por el cual se suspende el cronograma previsto en el Acuer- do PSA13-10073 del 27 de diciembre de 2013. Mayo 27 de 2014.

11. Acuerdo No. PSAA 14-10195 [Consejo Superior de la Judicatura]. Por el cual se recopilan, ajustan y adoptan unas medidas de descongestión. Julio 31 de 2014.

12. Acuerdo No. PSAA 14-10197 [Consejo Superior de la Judicatura]. Por el cual se adoptan unas medidas de descongestión. Agosto 5 de 2014.

13. Acuerdo No. PSAA14-10251 [Consejo Superior de la Judicatura]. Por el cual se prorrogan, ajustan y adoptan unas medidas de descongestión. Noviembre 14 de 2014.

14. Ávila Palacios, R. (12 de enero de 2014). Faltan $\$ 2$ billones para nueva justicia civil. Obtenido de: http://www.elespectador. $\mathrm{com} /$ noticias/judicial/faltan-2-billonesnueva-justicia-civil-articulo-468123

15. Caracol Radio. (20 de octubre de 2014). Fiscalía y sindicato de Asonal se reunirán para discutir paro judicial. Obtenido de: http:// caracol.com.co/radio/2014/10/20/judicial/1413791760_469503.html

16. Clavijo, S. (Octubre de 2011). Costos y eficiencia de la Rama Judicial en Colombia, políticas de choque operativo. Bogotá: Asociación Nacional de Instituciones Financieras. Obtenido de anif: http://anif.co/sites/ default/files/uploads/LIBROJUSTICIA-11. pdf 
17. Colprensa. (12 de agosto de 2013). Juzgados de descongestión podrían ser cargos permanentes. Obtenido de: http://www.elcolombiano.com/historico/juzgados_de_ descongestion_podrian_ser_cargos_permanentes-LCEC_255248

18. Consejo Superior de la Judicatura. (2004). Atraso judicial en Colombia: realidades y soluciones. Bogotá: Autor.

19. Consejo Superior de la Judicatura. (Marzo de 2010). Informe al Congreso de la República 2009-2010. Bogotá: Autor.

20. Consejo Superior de la Judicatura. (Marzo de 2011). Informe al Congreso de la República 2010-2011. Bogotá: Autor.

21. Consejo Superior de la Judicatura. (2012a). Informe al Congreso de la República 2011. Bogotá: Autor.

22. Consejo Superior de la Judicatura.(2012b). Informe al Congreso de la República 2012. Bogotá: Autor.

23. Consejo Superior de la Judicatura. Sala Administrativa. (Diciembre 2012c). Plan de Acción para la Implementación del Código General del Proceso (proyecto). Bogotá: Autor.

24. Consejo Superior de la Judicatura. (Mayo de 2013a). Primer ajuste al Plan de Acción para la Implementación del Código General del Proceso (proyecto). Bogotá: Autor.
25. Consejo Superior de la Judicatura. (2013b). Informe al Congreso de la República. Gestión de la administración de justicia año 2013. Bogotá: Autor.

26. Consejo Superior de la Judicatura. (Marzo 17 de 2015). Informe al Congreso de la República 2014. Bogotá: Autor.

27. Consejo Superior de la Judicatura. Sala Administrativa. (2013). Primer ajuste Plan de Acción para la Implementación del Código General del Proceso (Proyecto). Obtenido de: http://www.nuevalegislacion. com/-complementos/-anx_ac9927_13.pdf

28. Corporación Excelencia en la Justicia. (2007). Línea de Base de la Congestión Judicial en la Jurisdicción Ordinaria. (Ficha resumen). Disponible en: https://sinergia.dnp.gov.co/Sinergia/ Archivos/0818c0d8-f282-4ea5-b23a-edc9364b5e11/Ficha_congesti\%C3\%B3n_judicial_en_la_jurisdicci\%C3\%B3n_ordinaria.pdf

29. Corte Constitucional de Colombia. Sentencia C-100 de 2001 (M. P.: Martha Sáchica: enero 31 de 2011).

30. Corte Constitucional de Colombia. Sentencia C-334 de 2012 (M. P.: Mauricio González Cuervo: mayo 9 de 2012).

31. Departamento Nacional de Planeación. (2011). Bases del Plan Nacional de Desarrollo 2010-2014. Prosperidad para todos. 
Obtenido de: https://www.dnp.gov.co/PlanNacional-de-Desarrollo/PND-2010-2014/ Paginas/Plan-Nacional-De-2010-2014. aspx

32. El Tiempo. (12 de agosto de 2013). Jueces de descongestión dejarían de ser temporales. Obtenido de El Tiempo: http://www. eltiempo.com/justicia/ARTICULO-WEBNEW_NOTA_INTERIOR-12988649.htmI

33. Jiménez Herrera, J. S. (3 de agosto de 2014). Vuelve el fantasma del paro judicial. Obtenido de: http://www.elespectador. $\mathrm{com} /$ noticias/judicial/vuelve-el-fantasmadel-paro-judicial-articulo-508392

34. La W. (20 de octubre de 2014). Rama Judicial pedirá reunión urgente con Santos. Obtenido de W Radio: http://www. wradio.com.co/noticias/actualidad/ramajudicial-pedira-reunion-urgente-con-santos/20141020/nota/2470390.aspx

35. Ley 1285 de 2009. Por medio de la cual se reforma la Ley 270 de 1996 Estatutaria de la Administración de Justicia. Enero 22 de 2009. DO. No 47.240.

36. Ley 1395 de 2010. Por la cual se adoptan medidas en materia de descongestión judicial. Julio 12 de 2010. DO. No 47.768.

37. Ley 1437 de 2011. Por la cual se expide el Código de Procedimiento Administrativo y de lo Contencioso Administrativo. Enero 18 de 2011. DO. № 47.956.
38. Ley 1564 de 2012. Por la cual se expide el Código General del Proceso y se dictan otras disposiciones. Julio 12 de 2012. Do. $\mathrm{N}^{\circ} 48.489$.

39. Londoño, M. (2008). La congestión y la mora judicial: el juez, ¿su único responsable? Revista Facultad de Derecho y Ciencias Políticas, 38(109), 385-419. Obtenido de revistas: https://revistas.upb.edu.co/ index.php/derecho/article/view/669

40. McConville, M. (2007). Research methods for law. Edinburgh: Edinburgh University Press.

41. Ministerio de Justicia. (Septiembre 16 de 2011). Expediente Judicial Electrónico. Informes de Modernización Judicial en España. Madrid: Ministerio de Justicia. Obtenido de administraciondejusticia: https:// www.administraciondejusticia.gob.es/ paj/PA_WebApp_SGNTJ_NPAJ/descarga/ NL\%2019.\%20PRIMER\%20ANIVERSARIO\%20NOJ.pdf?idFile=fbdc64bc-89cc4c9b-8035-4664da64074c

42. Moreno Moreno, L. A. y Malagón Martínez, L. A. (2008). Unificación de procedimientos y sus términos procesales en materia civil como solución a la congestión de despachos judiciales en Bogotá, D.C. Bogotá: Universidad La Gran Colombia.

43. Piñeros, A. (Mayo de 2012). "Reforma a la justicia” ¿el remedio para la congestión judicial colombiana? Disponible en 
derechocomparado: http://derechocomparado-uniandes.blogspot.com/2012/05/ reforma-la-justicia-el-remedio-la.html

44. Ragin, C. (2007). La construcción de la investigación social, introducción a los métodos y su diversidad. Bogotá: Siglo del Hombre Editores/Universidad de los Andes.

45. Redacción Justicia. (12 de agosto de 2013). Jueces de descongestión dejarían de ser temporales. Obtenido de: http:// www.eltiempo.com/archivo/documento/ CMS-12988649

46. Redacción Política. (24 de septiembre de 2014). Aprueban eliminación del Consejo Superior de la Judicatura. Obtenido de: http://www.elespectador.com/noticias/ politica/aprueban-eliminacion-del-consejo-superior-de-judicatura-articulo-518651

47. Reyes, Y. (Octubre 17 de 2014). Palabras durante el foro Reforma a la Justicia: Retos y perspectivas, organizado por el Grupo de Interés Público de la Universidad de los Andes.

48. Rojas Gómez, M. E. (2011). Apuntes sobre la ley de descongestión (Segunda ed.). Bogotá.

49. Santos, P. (2005). Cifrar y Descifrar. Indicadores Judiciales para las Américas (Vol.
II.). Madrid: Centro de Estudios de Justicia de las Américas. Obtenido de oas: http:// www.oas.org/dsp/documents/cifrar_descifrar2_esp.pdf

Torres Calderón, L. A. (2002). Reflexiones sobre la congestión judicial en la jurisdicción contencioso administrativo coIombiana. Díkaion, 16(11), 57-7. Obtenido de redalyc: http://www.redalyc.org/ pdf/720/72001103.pdf

50. Unión Europea. (2006). La justicia en Nicaragua. Diagnóstico del sistema de justicia. Obtenido de: http://www.poderjudicial. gob.ni/arc-pdf/La\%20justicia\%20en\%20 Nicaragua\%20270906.pdf

51. Vega de Herrera, M. (s.f.). Despachos de descongestión y crisis de la justicia. Obtenido de: http://www.ambitojuridico.com/BancoConocimiento/N/ noti-140820-05despachos_de_descongestion/noti-140820-05despachos_de_ descongestion.asp?print=1

52. Younes Moreno, D. y Mejía Moreno, M. A. (2006). Estrategias para la descongestión en lo contencioso administrativo: proceso modelo y proceso testigo. En Colección Reformas en la Rama Judicial (tomo III), Bogotá: Deutsche Gesellschaft für Technische Zusammenarbeit (GTZ). 